\title{
Separation and Purification of Four Stilbenes from Vitis vinifera L. cv. Cabernet Sauvignon Roots Through High-speed Counter- current Chromatography
}

\author{
Yangji Wei ${ }^{1}$, $\mathrm{Pi} \mathrm{Li}^{1}$, Liyan $\mathrm{Ma}^{2,3}$, Jingming $\mathrm{Li}^{1 *}$
}

(1) Centre for Viticulture and Enology, College of Food Science and Nutritional Engineering, China Agricultural University, Beijing, 100083, P.R. China

(2) College of Food Science and Nutritional Engineering, China Agricultural University, Beijing, 100083, P.R. China

(3) Supervision and Testing Centre of Agricultural Product Quality, Ministry of Agriculture, Beijing, 100083, P.R. China

Date of submission for publication: December 2013

Date of acceptance for publication: March 2014

Keywords: HSCCC; $\varepsilon$-viniferin; trans-vitisin B; Vitis vinifera L. Cabernet Sauvignon
Abbreviations: HSCCC, high-speed counter-current chromatography
HPLC, high performance liquid chromatography
NMR, nuclear magnetic resonance

\begin{abstract}
A method for preparative separation and purification of trans-resveratrol, $\delta$-viniferin, $\varepsilon$-viniferin and trans-vitisin B from the roots of Vitis vinifera L. cv. Cabernet Sauvignon was successfully established and is reported on in this paper. The four important stilbenes were purified by high-speed counter-current chromatography (HSCCC) with a suitable quaternary solvent system composed of chloroform-methanol$n$-butanol-water $(4: 3: 0.05: 2, \mathrm{v} / \mathrm{v})$. A total of $7.1 \mathrm{mg} \pm \mathbf{0 . 2} \mathrm{mg}$ of trans-resveratrol, $1.1 \mathrm{mg} \pm \mathbf{0 . 1} \mathrm{mg} \mathrm{of}$ $\delta$-viniferin, $18.7 \mathrm{mg} \pm \mathbf{0 . 5} \mathrm{mg}$ of $\varepsilon$-viniferin, and $12.2 \mathrm{mg} \pm \mathbf{0 . 2} \mathrm{mg}$ of trans-vitisin $\mathrm{B}$, with purities of $97.89 \%$, $\mathbf{9 0 . 6 1 \%}, \mathbf{9 4 . 3 7 \%}$ and $\mathbf{7 8 . 3 8 \%}$ respectively, were obtained from $241 \mathrm{mg}$ of crude sample in ane-step HSCCC separation. The chemical structures of trans-resveratrol and $\delta$-viniferin were further confirmed with the retention time using the method of standard addition, while the structural identification of $\varepsilon$-viniferin and trans-vitisin B was performed with LC-ESI/MS, ${ }^{1} \mathrm{H}-\mathrm{NMR}$, and ${ }^{13} \mathrm{C}-\mathrm{NMR}$.
\end{abstract}

\section{INTRODUCTION}

Stilbenes, an important subclass of polyphenolic compounds (Guebailia et al., 2006) that include resveratrol, resveratrol glycoside, methylated resveratrol and viniferins, are phytoalexins found in grapes and other food products (Jang et al., 1997). All resveratrol oxidation products, which consist of dimers, trimers and the more highly polymerised oligomers of resveratrol, are known as viniferins. The bioactivities of resveratrol glycoside and viniferins have been studied less than resveratrol because their concentrations in grapes and wine are lower than those of resveratrol; however, some of their health-promoting properties have been found (Murias et al., 2005; Kuo \& Hsu, 2008; Guerrero et al., 2009). Extensive studies have shown that stilbenes have several useful biological properties, such as antiinflammatory, anti-asthmatic (Lee et al., 2009), anti-cancer (Jang et al., 1997), anti-HIV (Bedoya et al., 2006), anticardiovascular diseases (Ong et al., 2011), hepatoprotective (Lee et al., 2012) and anti-depressant activities (Yáñez et al., 2006), and that they protect against ethanol-induced oxidative DNA damage (Yan et al., 2012) and amyloid fibril formation (Rivière et al., 2010). Grapes are one of the most important potential sources of resveratrol for humans. Grapes (genus Vitis of family Vitaceae) are rich sources of stilbenes, especially resveratrol oligomers (He et al., 2009). Resveratrol and resveratrol glycoside compounds are often reported in wine (Bavaresco et al., 2003; Paulo et al., 2011). Paulo et al. (2011) analysed 186 Portuguese red wines and found that their trans-resveratrol content ranged from 0.05 $\mathrm{mg} \mathrm{L}^{-1}$ to $10.9 \mathrm{mg} \mathrm{L}^{-1}$ (Paulo et al., 2011). However, some studies have shown that the types of stilbenes in wine differ and that their content is less than in grape stems and roots (Pezet et al., 1994; Wang et al., 2010; Vergara et al., 2012). Thus, grape stems and roots are potential sources of stilbenes for separation and purification.

HSCCC is a support-free liquid-liquid partition chromatography, in which both the mobile and the stationary phase are liquids. HSCCC has significant advantages over other special separation techniques, which eliminate the irreversible adsorptive sample loss, stationary phase deactivation and tailing of solute peaks because of the surface overloading of silanol (Yao et al., 2012). In addition,

*Correspondingauthor: lyma@cau.edu.cn [Tel./fax: +86 10 62737553]

Acknowledgements: This work was financially supported by the Natural Science Foundation of China (No. 31171786), the Special Fund for Agro-scientific Research in the Public Interest (No. 201303076-03) and the China Agriculture Research System (CARS-30) 
HSCCC can handle large sample loads, has high recovery, and is scalable (Fang et al., 2011). The closed separation system protects the thermosensitive and photosensitive bioactive samples; hence, it is well suited for studying bioactive natural products. In recent years, HSCCC has been widely used in research on and the development of natural medicines and functional foods, including phytosterols (Schröder \& Vetter, 2011), minor saponins (Ha et al., 2011), essential oils (Chen et al., 2011), epigallocatechin gallate (Du et al., 2000), gingerols and 6-shogaol (Qiao \& Du, 2011), neohesperidin (Zhang et al., 2012), Alpinia katsumadai hayata flavonoids (Xiao et al., 2011), tanshinone (Tian et al., 2000; Sun et al., 2011), ginsenosides (Shehzad et al., 2012), and 6,7-dimethoxycoumarin (He et al., 2012). The chloroform-methanol-water solvent system was used to isolate resveratrol (Chen et al., 2001), the cyclohexaneethyl acetate-methanol-water solvent system was used to isolate stilbene glucosides (Fan et al., 2009), n-hexane-ethyl acetate-methanol-water solvent system was used to isolate hopeaphenol, amurensin G and vitisin A (He et al., 2009); and the ethyl acetate-ethanol-water solvent system was used to isolate stilbene glucoside and catechin (Jin \& Tu, 2005).

The purpose of this work was to establish a very convenient and efficient method for the rapid separation of stilbenes from the roots of Vitis vinifera L. cv. Cabernet Sauvignon. Firstly, four stilbenes from the roots of grapevines were isolated by HSCCC and semi-preparative high-performance liquid chromatography. Secondly, the trans-resveratrol and the $\delta$-viniferin were identified via UV detection and compared with standards. The chemical structures of $\varepsilon$-viniferin and trans-vitisin B (Fig. 1) were positively identified via UV detection, LC-ESI-MS/MS, ${ }^{1} \mathrm{H}$ NMR and ${ }^{13} \mathrm{C}$ NMR. This is the first report on the separation of four stilbenes from the roots of Vitis vinifera L. cv. Cabernet Sauvignon using this combination of techniques.

\section{MATERIALS AND METHODS \\ Reagents and materials}

All solvents used to prepare the crude samples and separate the HSCCC were of analytical grade and obtained from Beijing Beihua Fine Chemicals Company (Beijing, China). Chromatography grade solvents were purchased from $\mathrm{J} \&$ K Technology Co., Ltd. (Beijing, China). The water was prepared using a Milli-Q system (Molsheim, France). The trans-resveratrol standard was purchased from SigmaAldrich (Sigma-Aldrich, St. Louis, MO). The $\delta$-viniferin standard was prepared in our laboratory and its chemical structure was identified via UV, LC-ESI-MS/MS and NMR and compared with a reference (Pezet et al., 2003).

Two-year-old roots of $V$. vinifera $L$. Cabernet Sauvignon
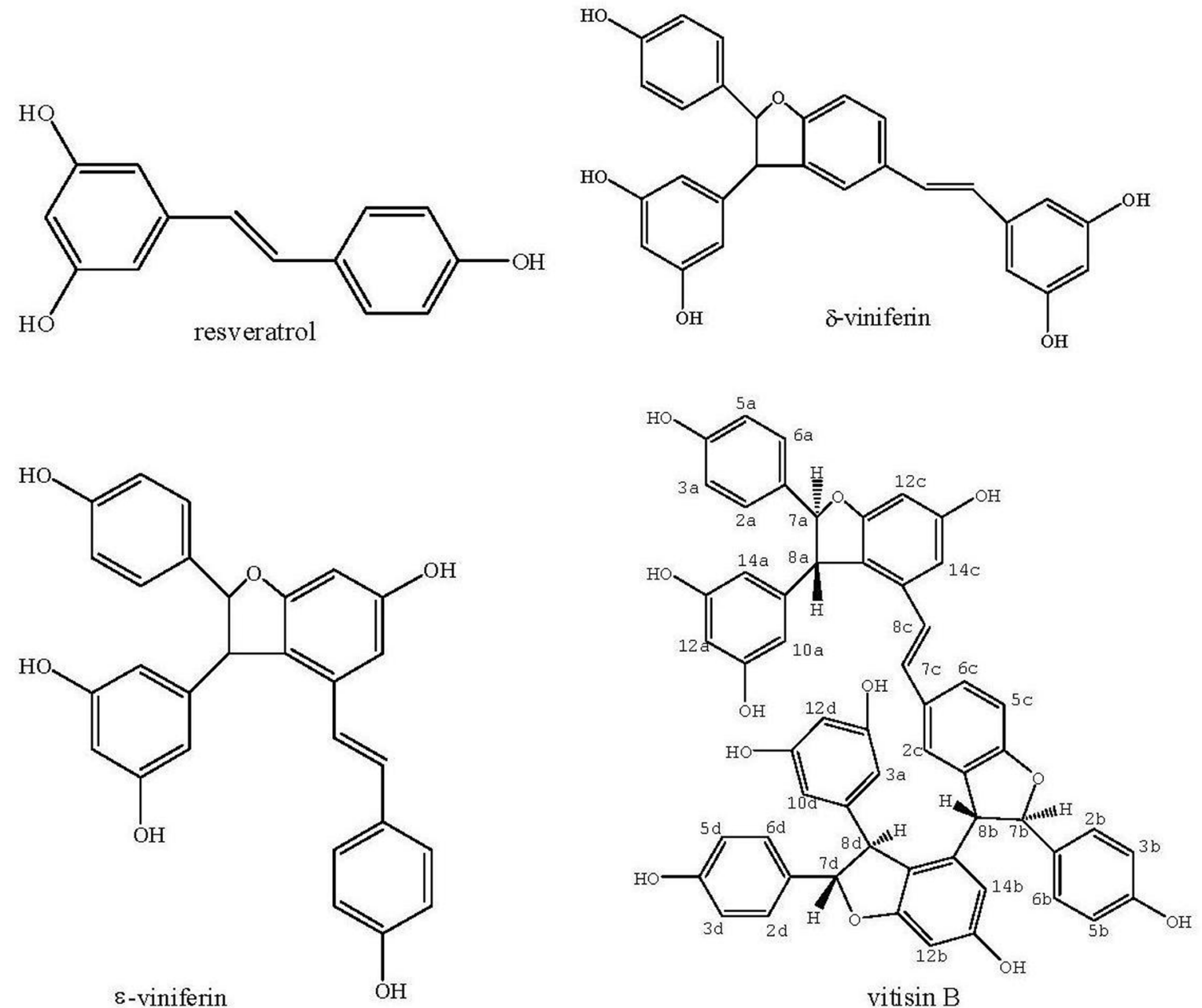

FIGURE 1

Chemical structures of trans-resveratrol, $\delta$-viniferin, $\varepsilon$-viniferin and trans-vitisin B. 
were collected from the Shangzhuang Experiment Station (China Agricultural University, Beijing, China).

\section{Apparatus}

A TBE-300B HSCCC (Shanghai Tauto Biotech Co., Ltd., Shanghai, China) equipped with three multilayer polytetrafluoroethylene coil separation columns $(1.6 \mathrm{~mm}$ tube diameter, $280 \mathrm{~mL}$ total column volume) and a $20 \mathrm{~mL}$ sample injection loop was used in this study. The revolution radius was $5 \mathrm{~cm}$ and the resulting $\beta$-value of the multilayer coil ranged from 0.5 at the internal terminal to 0.8 at the external terminal $(\beta=r / R$, where $r$ is the distance from the coil to the holder shaft). The HSCCC system was equipped with a TBP5002 constant flow pump (Shanghai Tauto Biotech Co., Ltd., Shanghai, China) and a 313 nm TBD-2000 UV detector (Shanghai Tauto Biotech Co., Ltd., Shanghai, China). The separation temperature was controlled using an HX-105 water-circulating constant temperature implement (Beijing Changliu Scientific Instruments Company, Beijing, China). The chromatogram was recorded using a WH500USB workstation (Tauto Biotechnique Company, Shanghai, China). The HPLC equipment was a Shimadzu LC-20AT system with an LC-20AT solvent delivery unit, an SPD-20A detector, a Rheodyne $7725 \mathrm{i}$ injection valve with a $20 \mu \mathrm{L}$ loop, and LabSolutions/LCsolution software (Shimadzu, Tokyo, Japan). The ESI mass spectra were obtained using an Agilent 6460 Triple Quadrupole HPLC-ESI-MS/MS instrument (Agilent Technologies, USA). The proton and carbon NMR and HSQC spectra were recorded on a Bruker Avance 600 spectrometer (Germany), with $\mathrm{Me}_{4} \mathrm{Si}$ as internal standard, in $\mathrm{CD}_{3} \mathrm{OD}$.

\section{Preparation of the crude sample solution}

About $100 \mathrm{~g}$ of the freeze-dried root powder (20 mesh to 30 mesh) of $V$. vinifera L. Cabernet Sauvignon was extracted twice for 12 min with $1 \mathrm{~L}$ of methanol-water solution under ultrasonication $\left(80 \mathrm{kHz},<30^{\circ} \mathrm{C}\right)(70: 30, \mathrm{v} / \mathrm{v})$ per extraction, and then placed in a refrigerator protected from light for $1 \mathrm{~h}$ at $4^{\circ} \mathrm{C}$. Both extracted solutions were combined and evaporated using a rotary evaporator at $35^{\circ} \mathrm{C}$ under vacuum. The residue was suspended in $300 \mathrm{~mL}$ of $3 \% \mathrm{NaHCO}_{3}(\mathrm{w} / \mathrm{v})$ and extracted three times with $200 \mathrm{~mL}$ of ethyl acetate. The extracts were then pooled and evaporated using a rotary evaporator at $35^{\circ} \mathrm{C}$ under vacuum. The $1.8691 \mathrm{~g}$ crude extract was stored at $-40^{\circ} \mathrm{C}$ for the subsequent experiments.

\section{HSCCC}

\section{Preparation of the two-phase solvent system}

The two-phase solvent system was selected according to the partition coefficients $(K)$ of each stilbene. The $K$ values were determined via HPLC as follows: $2 \mathrm{mg}$ of crude extract was dissolved in $2 \mathrm{~mL}$ of pre-equilibrated solvent system (upper phase/lower phase, 1:1 v/v). The tube was then shaken vigorously for $3 \mathrm{~min}$. After equilibration, the stilbene content $(500 \mu \mathrm{L})$ of the upper phase and the lower phase was analysed for the target compounds, and the areas of their HPLC peaks were recorded as $\mathrm{A}_{\text {upper }}$ and $\mathrm{A}_{\text {low }}$ respectively. The $K$ value was calculated as follows: $K=\mathrm{A}_{\text {upper }} / \mathrm{A}_{\text {low }}$.

\section{HSCCC separation procedure}

A two-phase solvent system composed of chloroform, methanol, $n$-butyl alcohol and water $(4: 3: 0.05: 2, \mathrm{v} / \mathrm{v})$ was selected to separate the stilbenes from the crude $V$. vinifera extract. The column was first filled entirely with the upper phase, which was used as the stationary phase. After the column was filled with the upper phase, the lower phase was pumped into the column from top to bottom at a flow rate of $2.5 \mathrm{~mL} / \mathrm{min}$, while the apparatus was rotated at 900 $\mathrm{rpm}$. After reaching hydrodynamic equilibrium, $10 \mathrm{~mL}$ of the sample solution $(24 \mathrm{mg} / \mathrm{min})$ was injected into the column using an injection valve and signal acquisition was started. The effluent from the tail end of the column was continuously monitored through UV detection at $313 \mathrm{~nm}$. The separated peak fractions were collected manually according to the chromatographic profiles. All experiments were completed at room temperature.

\section{Semi-preparative HPLC purification}

The liquid chromatography (LC) system consisted of a pump (LC-20 AT) and a diode array detector (SPD-M20A), both purchased from Shimadzu (Shimadzu, Tokyo, Japan). Data acquisition was performed by LabSolutions/LCsolution software (Shimadzu, Tokyo, Japan). The analytical column was a Venusil XBP C18 $(250 \mathrm{~mm} \times 10 \mathrm{~mm}, 5 \mu \mathrm{m}$; Agela Technologies, Tianjin, China). The detector wavelength setting was $306 \mathrm{~nm}$. An isocratic elution method with $40 \%$ acetonitrile solution $(\mathrm{v} / \mathrm{v})$ at a flow rate of $3 \mathrm{~mL} / \mathrm{min}$ was used. The peak fractions were collected manually according to the chromatographic profiles.

\section{Identification of HSCCC peak fractions}

The extracts and purified compounds were analysed on a Pinnacle II C18 column $(250 \mathrm{~mm} \times 4.6 \mathrm{~mm}, 5 \mu \mathrm{m}$; Restek, USA). The mobile phase consisted of ultrapure water (A) and acetonitrile (B). The elution was performed using the following gradient profile: $20 \%$ B keep $5 \mathrm{~min} ; 5 \mathrm{~min}$ to $21 \mathrm{~min}, 20 \%$ to $38 \% \mathrm{~B} ; 21 \mathrm{~min}$ to $38 \mathrm{~min}, 38 \%$ to $50 \% \mathrm{~B}$; $38 \mathrm{~min}$ to $42 \mathrm{~min}, 50 \%$ to $85 \% \mathrm{~B}$; $42 \mathrm{~min}$ to $45 \mathrm{~min}, 85 \%$ to $20 \% \mathrm{~B}$; and held until $50 \mathrm{~min}$. The flow rate of the mobile phase was $1 \mathrm{~mL} \mathrm{~min}^{-1}$.

During the ESI-MS analysis, the MS was operated in multiple reaction monitoring mode. Source parameter: gas temperature $325^{\circ} \mathrm{C}$; gas flow $6 \mathrm{~L} \mathrm{~min}^{-1}$; nebuliser $45 \mathrm{psi}$; sheath gas temperature $350^{\circ} \mathrm{C}$; sheath gas flow $11 \mathrm{~L} / \mathrm{min}$; capillary positive $3000 \mathrm{~V}$, negative $3000 \mathrm{~V}$; nozzle positive $500 \mathrm{~V}$, negative $1000 \mathrm{~V}$; collision energy, trans-resveratrol $25 \mathrm{~V} / 15 \mathrm{~V}, \quad \delta$-viniferin $14 \mathrm{~V} / 22 \mathrm{~V}$, $\varepsilon$-viniferin $20 \mathrm{~V} / 36 \mathrm{~V}$, and trans-vitisin B 30V.

\section{Statistical analysis}

The data represent means $\pm \mathrm{SD}$ of three independent HSCCC experiments.

\section{RESULTS AND DISCUSSION}

HPLC analysis and selection of the two-phase solvent system

The most important step in the design of an HSCCC separation system is the selection of the solvent system. 
Generally, two-phase solvent systems need to satisfy the following requirements: (1) the settling time of the solvent system should ideally be shorter than $30 \mathrm{~s}$ to ensure satisfactory retention of the stationary phase; (2) the partition coefficient $(K)$ of the target compounds should be $0.5 \leq K \leq$ 2.0 for efficient separation; (3) the separation factor between the two components $(\alpha=\mathrm{K} 2 / \mathrm{K} 1, \mathrm{~K} 2>\mathrm{K} 1)$ should be greater than 1.5 (Lee et al., 2011); and (4) the sample should not decompose or be denatured. In the current study, the $K$ values of the four stilbenes were determined via HPLC, as described in the experimental section (Table 1). The solvent system was chosen based on the following observations: the $n$-hexane-ethyl acetate-methanol-water $(1: 2: 1: 2, \mathrm{v} / \mathrm{v})$ solvent system provided suitable $K$ values for the peaks,

\section{TABLE 1}

The partition coefficient $(K)$ of the target components in different solvent systems.

\begin{tabular}{lllllll}
\hline & & \multicolumn{5}{c}{$K$ value } \\
\cline { 3 - 6 } No. & Two-phase solvent system (v/v) & 2.55 & 3.92 & 3.29 & 7.31 & 17 \\
\hline 1 & chloroform-methanol-water, 4:3:2 & resveratrol & $\varepsilon$-viniferin & $\delta$-viniferin & trans-vitisin B & Setting time (s) \\
2 & cyclohexane-ethyl acetate-methanol-water, 1:5:1:5 & 108.75 & 85 & - & 228.84 & 29 \\
3 & n-hexane-ethyl acetate-methanol-water, 2:5:2:5 & 9.76 & 26.4 & 22.92 & 59.34 & 33 \\
4 & n-hexane-ethyl acetate-methanol-water, 1:2:1:2 & 2.52 & 3.25 & 3.02 & 3.66 & 21 \\
5 & n-hexane-ethyl acetate-methanol-water, 2:5:1:2 & 6.79 & 10.5 & 11.71 & 17.39 & 29 \\
6 & ethyl acetate-ethanol-water, 25:1:25 & - & 92 & - & - & 20 \\
7 & ethyl acetate-ethanol-water, 5:1:5 & - & 102 & - & - & 19 \\
8 & chloroform-methanol- $n$-butyl alcohol-water 4:3:0.05:2 & 2.39 & 4.4 & 2.87 & 9.1 & 18 \\
\hline
\end{tabular}

a

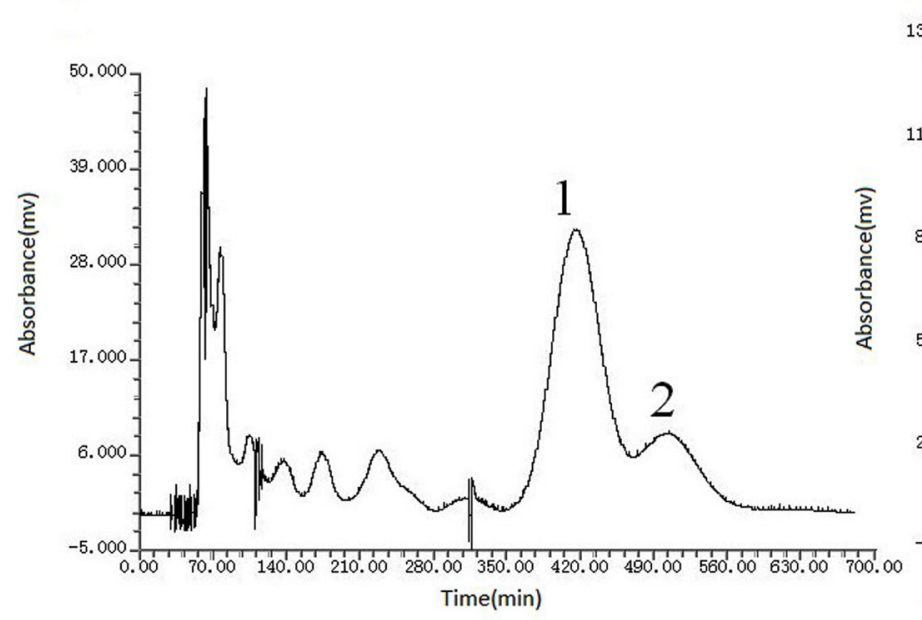

c

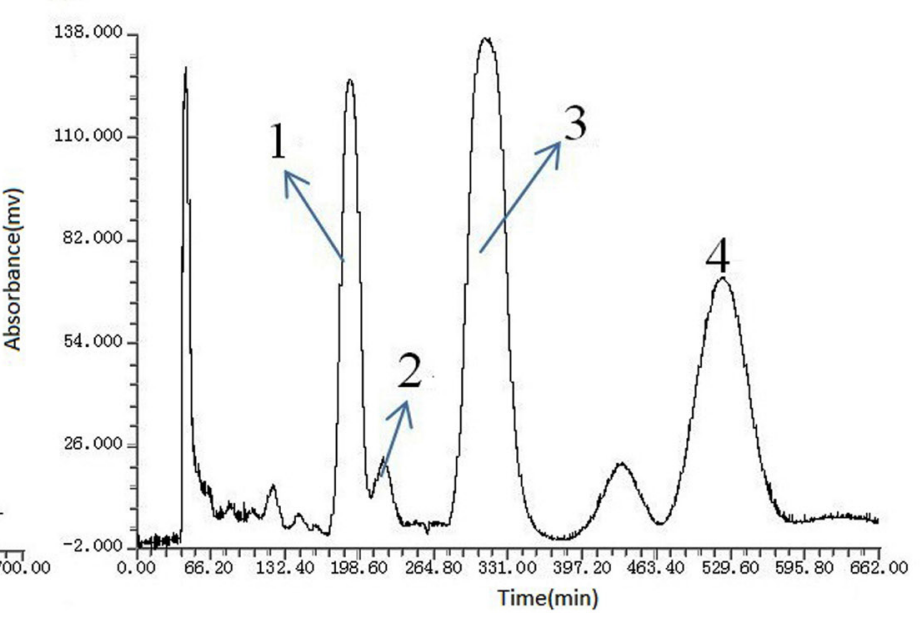

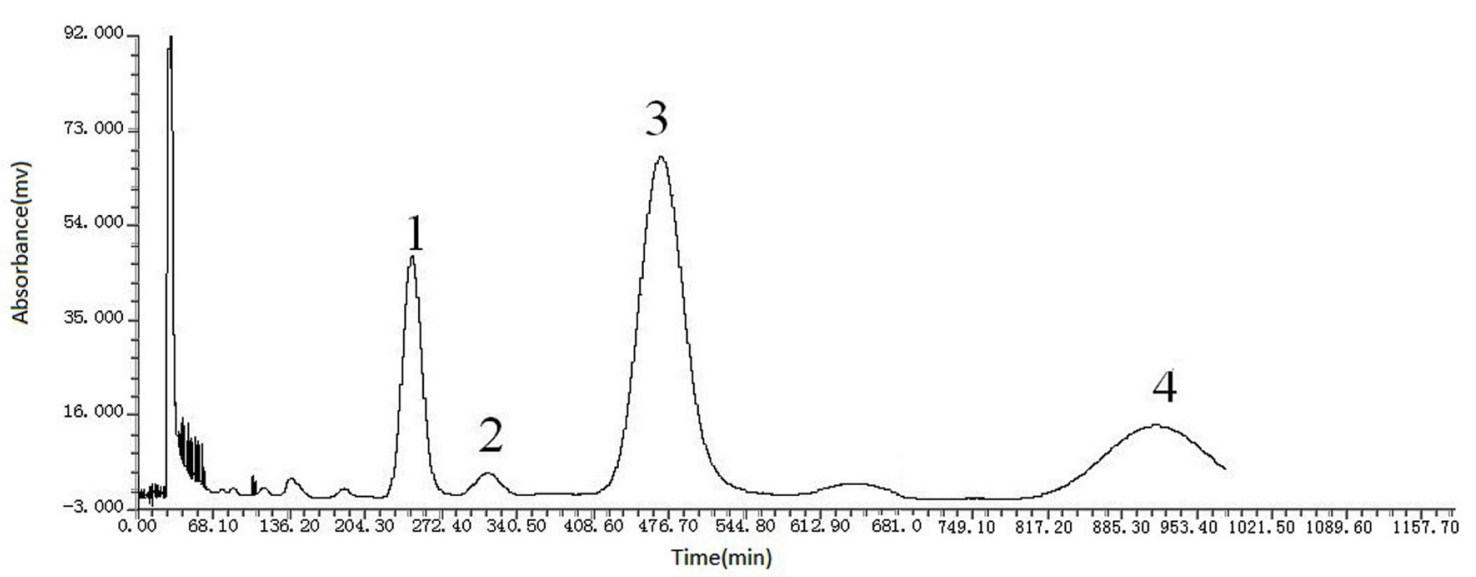

FIGURE 2

Preparative HSCCC separation of the crude sample from Vitis vinifera L. cv. Cabernet Sauvignon using (a) the two-phase solvent system composed of $n$-hexane-ethyl acetate-methanol-water $(1: 2: 1: 2, \mathrm{v} / \mathrm{v})$; (b) the chloroform-methanol-water $(4: 3: 2$, $\mathrm{v} / \mathrm{v})$. The longest time recorded for the HSCCC procedure is $681 \mathrm{~min}$, so after the completion of the first program, the second record immediately start without new sample; and (c) chloroform-methanol- $n$-butyl alcohol-water (4:3:0.05:2, v/v). 


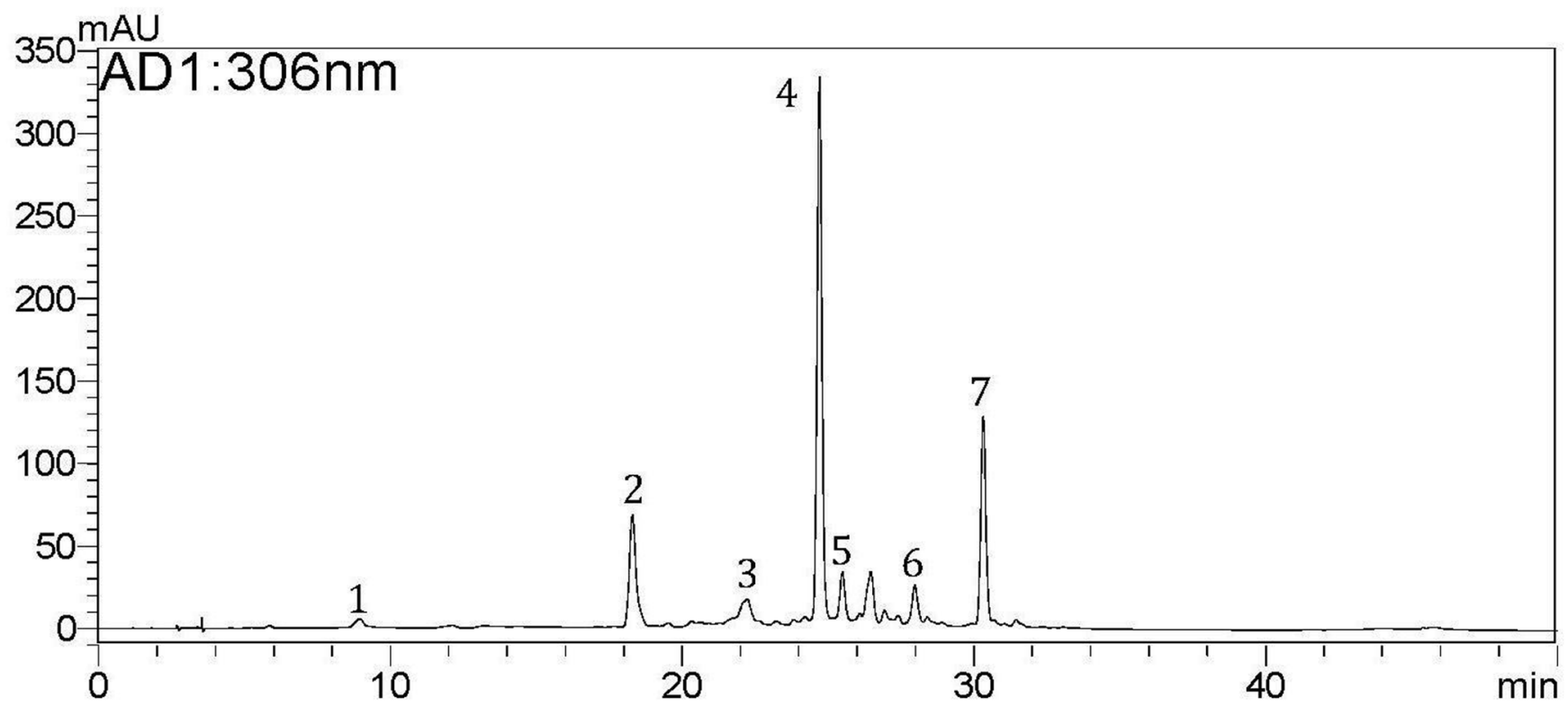

FIGURE 3

HPLC chromatograms of the crude extract from Vitis vinifera L. cv. Cabernet Sauvignon root. Peak 1 is piceid, 2 is transresveratrol, 3 is cis-resveratrol, 4 is compound 1,5 compound 3,6 is $\delta$-viniferin and 7 is compound 2.

which fulfilled requirement (2) mentioned above; however, this system provided a poor separation factor between these compounds. The chloroform-methanol-water $(4: 3: 2, \mathrm{v} / \mathrm{v})$ solvent system fulfilled requirement (3), but all the $K$ values were higher than 2.0. Thus, the suggested $n$-hexane-ethyl acetate-methanol-water $(1: 2: 1: 2, \mathrm{v} / \mathrm{v})$ (retention of the stationary was $61.43 \%$ ) needed a shorter separation time, but it was unable to separate the stilbenes sufficiently (Fig. 2a). This system provided two peaks that contained two or more of the compounds. The chloroform-methanol-water system $(4: 3: 2, \mathrm{v} / \mathrm{v})$ (retention of the stationary phase was $60.71 \%)$ could separate the four stilbenes well, but it required separation times longer than $15 \mathrm{~h}$ (Fig. 2b). Thus, this system would be feasible if the separation time was shortened. The polar modifier $n$-butyl alcohol was added to the chloroform solvent system and formed a new solvent system consisting of chloroform-methanol- $n$-butyl alcohol-water $(4: 3: 0.05: 2$, $\mathrm{v} / \mathrm{v})$. The new solvent system had a much shorter separation time and it sufficiently separated the four stilbenes, with good retention of the stationary phase $(58.93 \%)$.

Figure 3 shows HPLC chromatograms of the crude extract from the roots. There are seven peaks. Peak 1 is piceid, 2 is trans-resveratrol, 3 cis-resveratrol, 4 compound $1 ; 5$ compound $3,6 \delta$-viniferin, and 7 is compound 2 . Figure 2c shows the preparative HSCCC separation of $241 \mathrm{mg}$ of crude extract using the solvent system composed of chloroform-methanol- $n$-butyl alcohol-water $(4: 3: 0.05: 2$, v/v). Peak 1, from $172 \mathrm{~min}$ to $205 \mathrm{~min}$, peak 2, from $211 \mathrm{~min}$ to $237 \mathrm{~min}$, peak 3 , from $280 \mathrm{~min}$ to $345 \mathrm{~min}$, and peak 4 , from $476 \mathrm{~min}$ to $569 \mathrm{~min}$, were collected and concentrated. This separation yielded $7.1 \mathrm{mg} \pm 0.2 \mathrm{mg}$ of peak $1,1.1 \mathrm{mg}$ $\pm 0.1 \mathrm{mg}$ of peak $2,18.7 \mathrm{mg} \pm 0.5 \mathrm{mg}$ of peak 3 , and $12.2 \mathrm{mg}$ $\pm 0.2 \mathrm{mg}$ of peak 4 . Three independent experiments were carried out. Peaks 1, 2, 3 and 4 were identified as resveratrol, $\delta$-viniferin, compound 1 and compound 2 , with purities of
$97.89 \%, 90.61 \%, 94.37 \%$ and $78.38 \%$ respectively, based on the area percentage of the HPLC peak, as shown in Figs 4a to $4 \mathrm{~d}$. The lower purity of peak 4 was due to an unknown impurity. Peaks 3 and 4 from HSCCC separation were subjected to semi-preparative HPLC for further purification to obtain pure compounds. Two compounds were completely separated through the combined use of HSCCC and semipreparative high-performance liquid chromatography, and the purities of these compounds were $97.39 \%$ and $95.35 \%$ respectively, as indicated by the HPLC analysis based on PDA detection (Fig. 4e). Piceid and compound 3 of the crude extract were not collected and detected through HSCCC.

\section{Identification of compounds 1 and 2}

The chemical structures of the peak fractions separated by HSCCC were identified according to their ${ }^{1} \mathrm{H}-\mathrm{NMR}$ and ${ }^{13} \mathrm{C}-\mathrm{NMR}$ data. Based on the comparison with the reference data, peak 3 (compound 1) and peak 4 (compound 2) were identified as $\varepsilon$-viniferin and trans-vitisin $\mathrm{B}$ respectively. The results for each peak fraction were as follows.

Compound 1 (Peak 3 in Fig. 2c) was obtained as a pale yellow amorphous powder. ESI/MS/MS m/z: $455.1[\mathrm{M}+\mathrm{H}]+$ (calc. for $\mathrm{C}_{28} \mathrm{H}_{23} \mathrm{O}_{6}, 455.1$ ), $453.1[\mathrm{M}+\mathrm{H}]$ - (calc. for $\mathrm{C}_{28} \mathrm{H}_{21} \mathrm{O}_{6}$, 453.1), which was consistent with the molecular formula $\mathrm{C}_{28} \mathrm{H}_{22} \mathrm{O}_{6}$, which corresponds to the resveratrol dimer. The ${ }^{1} \mathrm{H},{ }^{13} \mathrm{C}$ NMR $(600 \mathrm{MHz})$ data were as follows: ${ }^{1} \mathrm{H}$ NMR $\delta$ : $7.14(2 \mathrm{H}, \mathrm{d}, \mathrm{J}=6.8 \mathrm{~Hz}), 7.04(2 \mathrm{H}, \mathrm{d}, \mathrm{J}=6.8 \mathrm{~Hz}), 6.77(2 \mathrm{H}$, $\mathrm{d}, \mathrm{J}=6.8 \mathrm{~Hz}), 6.64(2 \mathrm{H}, \mathrm{d}, \mathrm{J}=6.8 \mathrm{~Hz}), 6.82(1 \mathrm{H}, \mathrm{d}, \mathrm{J}=16.3$ $\mathrm{Hz}), 6.57(1 \mathrm{H}, \mathrm{d}, \mathrm{J}=16.1 \mathrm{~Hz}), 5.37(1 \mathrm{H}, \mathrm{d}, \mathrm{J}=4.9 \mathrm{~Hz}), 4.35$ $(1 \mathrm{H}, \mathrm{d}, \mathrm{J}=4.8 \mathrm{~Hz}), 6.18$ (3H, brs), $6.66(1 \mathrm{H}, \mathrm{brs}), 6.25(1 \mathrm{H}$, brs). 13C NMR $\delta$ : 133.91, 127.9 (2C), 116.31 (2C), 158.54, $94.83,58.31,136.93,107.49,160.06,102.22,160.06$, $107.49,130.41,128.78$ (2C), 116.38 (2C), 158.39, 130.35, $123.73,136.93,120.06,162.75,96.86,159.76,104.37$. The ${ }^{13} \mathrm{C}$ NMR data corresponded well with $\varepsilon$-viniferin, which has 


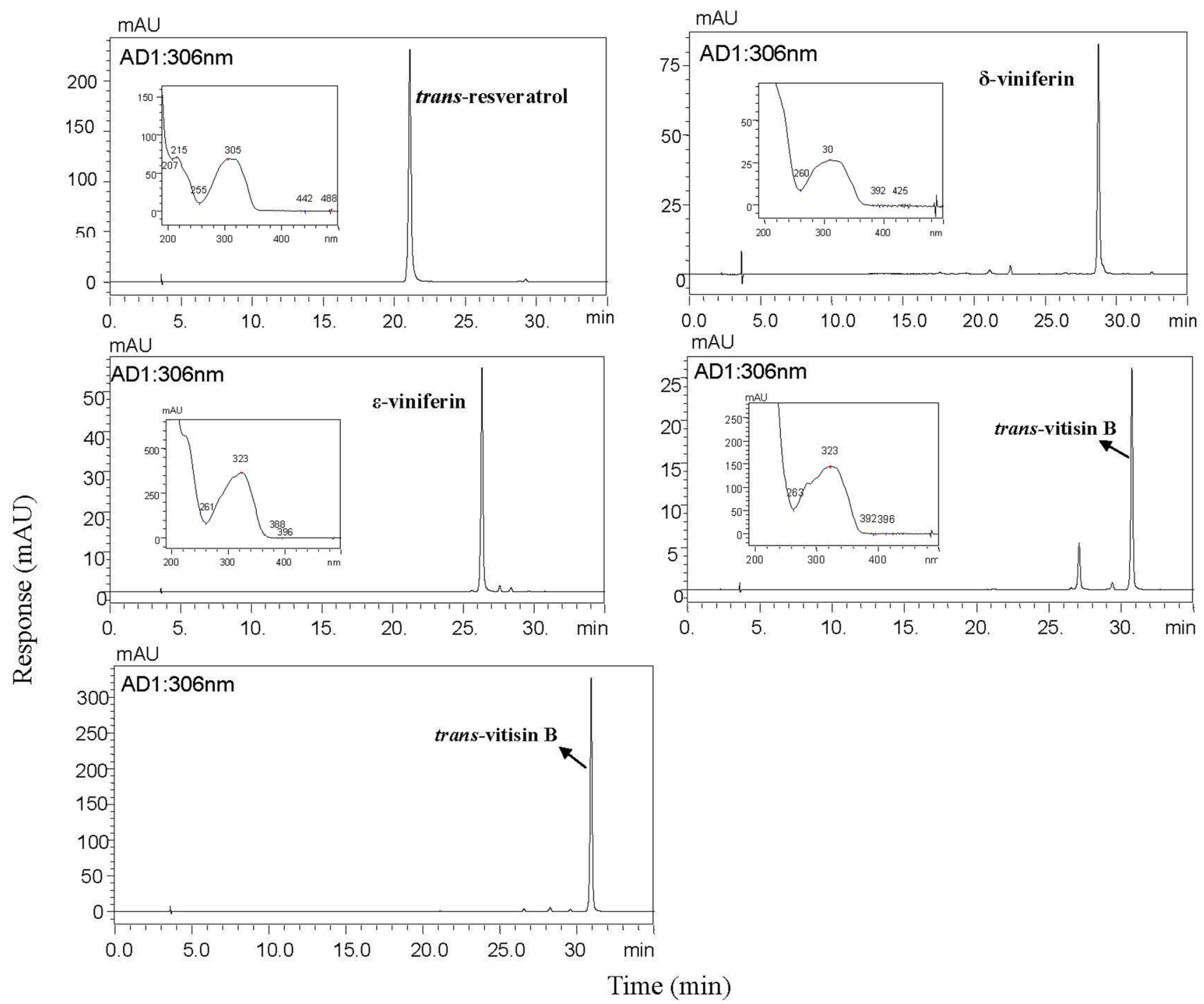

FIGURE 4

HPLC chromatograms and UV spectra of each separated peak. (a) HSCCC fraction of peak 1 in Fig. 2c, trans-resveratrol (97.89\% purity); (b) HSCCC fraction of peak 2 in Fig. 2c, $\delta$-viniferin (90.61\% purity); (c) HSCCC fraction of peak 3 in Fig. 2c, $\varepsilon$-viniferin (94.37\% purity); (d) HSCCC fraction of peak 4 in Fig. 2c, trans-vitisin B (78.38\% purity). The collected fractions from HSCCC were analysed by HPLC using the following conditions: column, a PINNACLE II C18 column (250 mm $\times$ $4.6 \mathrm{~mm}, 5 \mu \mathrm{m}$, Restek, USA); detection, $306 \mathrm{~nm}$. (e) trans-Vitisin B was separated from fraction 4 via semipreparative HPLC (95.35\% purity).

been reported in the literature ( $\mathrm{Li}$ et al., 1996). However, the ${ }^{1} \mathrm{H}$ NMR chemical shifts were not entirely consistent with $\varepsilon$-viniferin, as a $0.06 \mathrm{ppm}$ smaller downfield shift was observed for almost all of the data. In addition, the coupling constants relevant to the molecular structure were consistent with $\varepsilon$-viniferin. The spectrum exhibited 15 proton signals in the olefinic proton region ( $\delta=4.5$ to 8.5$)$, among which a pair of doublet signals at $\delta 6.82$ and $\delta 6.57$ were assigned to a pair of trans-olefinic protons, as shown by the coupling constants $(\mathrm{J}=16.3 \mathrm{~Hz}, 16.1 \mathrm{~Hz})$. Hydrogen chemical shift deviations may result from the different solvents. $\mathrm{CD}_{3} \mathrm{OCD}_{3}$ was used in the literature, whereas $\mathrm{CD}_{3} \mathrm{OD}$ was used in this paper. Active hydrogen is susceptible to the effects of $\mathrm{CD}_{3} \mathrm{OD}$, hence the changes in the chemical shifts. In addition, the UV spectra of compound 1 corresponded to $\varepsilon$-viniferin (Amira-Guebailia et al., 2009; Kong et al., 2011)
Compound 2 (Peak 4 in Fig. 2c) was obtained as pale amorphous powder. ESI/MS/MS m/z: $907.2[\mathrm{M}+\mathrm{H}]+$ (calc. for $\mathrm{C}_{56} \mathrm{H}_{43} \mathrm{O}_{12}, 907.2$ ), $905.2[\mathrm{M}+\mathrm{H}]-$ (calc. for $\mathrm{C}_{56} \mathrm{H}_{42} \mathrm{O}_{12}$, 905.2), which is consistent with the molecular formula $\mathrm{C}_{56} \mathrm{H}_{43} \mathrm{O}_{12}$, which corresponds to the resveratrol tetramer. The $1 \mathrm{H}, 13 \mathrm{C}$ NMR $(600 \mathrm{MHz})$ data were as follows: $1 \mathrm{H}$ NMR $\delta: 7.18(2 \mathrm{H}, \mathrm{d}, \mathrm{J}=8.4 \mathrm{~Hz}), 7.14(2 \mathrm{H}, \mathrm{d}, \mathrm{J}=8.4 \mathrm{~Hz})$, $6.99(1 \mathrm{H}, \mathrm{dd}, \mathrm{J}=8.2,1.8 \mathrm{~Hz}), 6.83(2 \mathrm{H}, \mathrm{d}, \mathrm{J}=8.4 \mathrm{~Hz}), 6.77$ $(2 \mathrm{H}, \mathrm{d}, \mathrm{J}=8.2 \mathrm{~Hz}), 6.66(1 \mathrm{H}, \mathrm{brs}), 6.69(1 \mathrm{H}, \mathrm{brs}), 6.68(1 \mathrm{H}$, $\mathrm{d}, \mathrm{J}=15.12 \mathrm{~Hz}), 6.58(1 \mathrm{H}, \mathrm{brs}), 6.51(1 \mathrm{H}, \mathrm{d}, \mathrm{J}=14.7 \mathrm{~Hz})$, $6.53(2 \mathrm{H}, \mathrm{d}, \mathrm{J}=6.6 \mathrm{~Hz}), 6.59(2 \mathrm{H}, \mathrm{d}, \mathrm{J}=8.8 \mathrm{~Hz}), 6.28(1 \mathrm{H}$, $\mathrm{d}, \mathrm{J}=2.2 \mathrm{~Hz}), 6.25(1 \mathrm{H}, \mathrm{d}, \mathrm{J}=2.1 \mathrm{~Hz}), 6.10(1 \mathrm{H}, \mathrm{d}, \mathrm{J}=2.2$ $\mathrm{Hz}), 6.14$ (3H, brs), $6.07(1 \mathrm{H}, \mathrm{t}), 5.98(2 \mathrm{H}, \mathrm{d}, \mathrm{J}=2.2 \mathrm{~Hz})$, $5.43(1 \mathrm{H}, \mathrm{d}, \mathrm{J}=5.1 \mathrm{~Hz}), 5.37(1 \mathrm{H}, \mathrm{d}, \mathrm{J}=6.6 \mathrm{~Hz}), 5.34(1 \mathrm{H}$, $\mathrm{d}, \mathrm{J}=4.6 \mathrm{~Hz}), 4.36(1 \mathrm{H}, \mathrm{d}, \mathrm{J}=4.5 \mathrm{~Hz}), 4.34(1 \mathrm{H}, \mathrm{d}, \mathrm{J}=6.5$ $\mathrm{Hz}), 4.25(1 \mathrm{H}, \mathrm{d}, \mathrm{J}=5.0 \mathrm{~Hz})$. 13C NMR $\delta: 127.78(2 \mathrm{C})$, 
$128.2(2 \mathrm{C}), 126.4,116.31(2 \mathrm{C}), 116.49(2 \mathrm{C}), 125.54,110.69$, $130.49,104.62,124.2,116.03(2 \mathrm{C}), 127.78(2 \mathrm{C}), 96.5$ $96.91,107.49,102.28,102.51,107.49,107.49,107$ (2C), $92.25,94.78,94.72,58.24,57.93,52.99$. Based on these data, compound 2 was confirmed as trans-vitisin B, which has been reported in the literature (Oshima et al., 1995).

\section{CONCLUSIONS}

In the present study, four similar stilbenes were successfully isolated for the first time from the roots of Vitis vinifera L. Cabernet Sauvignon, which has a higher stilbene level than wine of high purity, using conventional HSCCC. The crude extract of root was separated and purified directly by HSCCC using chloroform-methanol- $n$-butyl alcoholwater $(4: 3: 0.05: 2, \mathrm{v} / \mathrm{v})$ solvent system. This study was the first to separate $\delta$-viniferin, $\varepsilon$-viniferin and trans-vitisin B by using a single HSCCC method. The results of our study demonstrate that the method is a feasible, economical and efficient technique for the rapid preparative isolation of bioactive components from plant materials.

\section{LITERATURE CITED}

Amira-Guebailia, H., Valls, J., Richard, T., Vitrac, X., Monti, J.P., Delanay, J.C. \& Mérillon, J.M., 2009. Centrifugal partition chromatography followed by HPLC for the isolation of cis- $\varepsilon$-viniferin, a resveratrol dimer newly extracted from a red Algerian wine. Food Chem. 113, 320-324

Bavaresco, L., 2003. Role of viticultural factors on stilbene concentrations of grapes and wine. Drugs Exp. Clin. Res. 29,181-187.

Bedoya, L.M., Olmo, E.D., Sancho, R., Barboza, B., Beltrán, M., GarcíaCadenas, A.E., Sánchez-Palomino, S., López-Pérez, J.L., Muñoz, E. Feliciano, A.S. \& Alcamí, J., 2006. Anti-HIV activity of stilbene-related heterocyclic compounds. Bioorg. Med. Chem. Lett. 16, 4075-4079.

Chen, L., Han, Y.S., Yang, F.Q. \& Zhang, T.Y., 2001. High-speed countercurrent chromatography separation and purification of resveratrol and piceid from Polygonum cuspidatum. J. Chromatogr. A 907, 343-346.

Chen, Q.Q., Hu, X.F., Li, J.M., Liu, P., Yang, Y. \& Ni, Y.Y., 2011. Preparative isolation and purification of cuminaldehyde and p-menta-1,4-dien-7-al from the essential oil of Cuminum cyminum L. by high-speed counter-current chromatography. Anal. Chim. Acta. 689, 149-154.

Du, Q.Z., Wu, P.D. \& Ito, Y., 2000. Low-speed rotary countercurrent chromatography using a convoluted multilayer helical tube for industrial separation. Anal. Chem. 72, 3363-3365.

Fan, P.H., Marston, A., Hay, A.E. \& Hostettmann, K., 2009. Rapid separation of three glucosylated resveratrol analogues from the invasive plant Polygonum cuspidatum by high-speed countercurrent chromatography. J. Sep. Sci. 32, 2979-2984.

Fang, L., Liu, Y.Q., Yang, B., Wan, X. \& Huang, L., 2011. Separation of alkaloids from herbs using high-speed counter-current chromatography. J. Sep. Sci. 34, 2545-2558.

Guebailia, H.A., Chira, K., Richard, T., Mabrouk, T., Furiga, A., Vitrac, X., Monti, J.P., Delaunay, J.C. \& Mérillon, J.M., 2006. Hopeaphenol: The first resveratrol tetramer in wines from North Africa. J. Agric. Food Chem. 54, 9559-9564.

Guerrero, R.F., García-Parrilla, M.C., Puertas, B. \& Cantos-Villar, E., 2009 Wine, resveratrol and health: A review. Nat. Prod. Commun. 4, 635-656.

Ha, I.J., Kang, M., Na, Y.C., Park, Y. \& Kim, Y.S., 2011. Preparative separation of minor saponins from Platycodi Radix by high-speed countercurrent chromatography. J. Sep. Sci. 34, 2559-2565.
He, K., Ye, X.L., Li, X.G., Chen, H.Y., Yuan, L.J., Deng, Y.F., Chen, X. \& Li, X.D., 2012. Separation of two constituents from purple sweet potato by combination of silica gel column and high-speed counter-current chromatography. J. Chromatogr. B: Anal. Technol. Biomed. Life Sci. 881$882,49-54$

He, S., Lu, Y.B., Jiang, L.Y., Wu, B., Zhang, F.Y. \& Pan, Y.J., 2009. Preparative isolation and purification of antioxidative stilbene oligomers from Vitis chunganeniss using high-speed counter-current chromatography in stepwise elution mode. J. Sep. Sci. 32, 2339-2345.

Jang, M., Cai, L., Udeani, G.O., Slowing, K.V., Thomas, C.F., Beecher, C.W.W., Fong, H.H.S., Famsworth, N.R., Kinghorn, A.D., Mehta, R.G. \& Moon, R.C., 1997. Cancer chemopreventive activity of resveratrol, a natural product derived from grapes. Science 275, 218-220.

Jin, W. \& Tu, P.F., 2005. Preparative isolation and purification of trans3,5,4'-trihydroxystilbene-4'-O-beta-D-glucopyranoside and (+)catechin from Rheum tanguticum Maxim. ex Balf. using high-speed counter-current chromatography by stepwise elution and stepwise increasing the flow-rate of the mobile phase. J. Chromatogr. A 1092, 241-245.

Kong, Q.J., Ren, X.Y., Hu, N., Sun, C.R. \& Pan, Y.J., 2011. Identification of isomers of resveratrol dimer and their analogues from wine grapes by HPLC/MS ${ }^{n}$ and HPLC/DAD-UV. Food Chem. 127,727-734.

Kuo, P. \& Hsu, Y., 2008. The grape and wine constituent piceatannol inhibits proliferation of human bladder cancer cells via blocking cell cycle progression and inducing Fas/membrane bound Fas ligand-mediated apoptotic pathway. Mol. Nutr. Food Res. 52, 408-418.

Lee, C.W., Yen, F.L., Huang, H.W., Wu, T.H., Ko, H.H., Tzeng, W.S. \& Lin, C.C., 2012. Resveratrol nanoparticle system improves dissolution properties and enhances the hepatoprotective effect of resveratrol through antioxidant and anti-inflammatory pathways. J. Int. Immunopharmacol. 9 , 418-424

Lee, M., Kim, S., Kwon, O.K., Oh, S.R., Lee, H.K. \& Ahn, K., 2009. Antiinflammatory and anti-asthmatic effects of resveratrol, a polyphenolic stilbene, in a mouse model of allergic asthma. Agric. Food Chem. 60, 4662 4671

Lee, Y.S., Kim, S.H., Kim, J.K., Lee, S., Jung, S.H. \& Lim, S.S., 2011. Preparative isolation and purification of seven isoflavones from Belamcanda chinensis. Phytochem. Anal. 22, 468-473.

Li, W.W., Ding, L.S., Li, B.G. \& Chen, Y.Z., 1996. Oligostilbenes from Vitis heyneana. Phytochem. 42, 1163-1165.

Murias, M., Jaeger, W., Handler, N., Erker, T., Horvath, Z. \& Szekeres, T., 2005. Antioxidant, prooxidant and cytotoxic activity of hydroxylated resveratrol analogues: Structure-activity relationship. Biochem. Pharmacol. 69, 903-912.

Ong, E.T., Hwang, T.L., Huang, Y.L., Lin, C.F. \& Wu, W.B., 2011. Vitisin $\mathrm{B}$, a resveratrol tetramer, inhibits migration through inhibition of PDGF signaling and enhancement of cell adhesiveness in cultured vascular smooth muscle cells. Toxicol. Appl. Pharm. 256, 198-208.

Oshima, Y., Kamijou, A., Ohizumi, Y., Niwa, M., Ito, J., Hisamichi, K. \& Takeshita, M., 1995. Novel oligostilbenes from Vitis coignetiae. Tetrahedron 51, 11979-11986.

Paulo, L., Domingues, F., Queiroz, J.A. \& Gallardo, E., 2011. Development and validation of an analytical method for the determination of trans- and cis-resveratrol in wine: Analysis of its contents in 186 Portuguese red wines. J. Agric. Food Chem. 59, 2157-2168.

Pezet, R., Perret, C., Jean-Denis, J.B., Tabacchi, R., Gindro, K. \& Viret, O. 2003. $\delta$-Viniferin, a resveratrol dehydrodimer: One of the major stilbenes synthesized by stressed grapevine leaves. J. Agric. Food Chem. 51, 54885492.

Pezet, R., Pont, V. \& Cuenat, P., 1994. Method to determine resveratrol and pterostilbene in grape berries and wines using HPLC and highly sensitivity fluorimetric detection. J. Chromatogr. A 663, 191-197. 
Qiao, Q.L. \& Du, Q.Z., 2011. Preparation of the monomers of gingerols and 6-shogaol by flash high speed counter-current chromatography. J. Chromatogr. A 1218, 6187-6190.

Rivière, C., Papastamoulis, Y., Fortin, P.Y., Delchier, N., Andriamanarivo, S., Waffo-Teguo, P., Kapche, G.D.W.F., Amira-Guebalia, H., Delaunay, J.C., Mérillon, J.M., Richard, T. \& Monti, J.P., 2010. New stilbene dimers against amyloid fibril formation. Bioorg. Med. Chem. Lett. 20, 3441-3443.

Schröder, M. \& Vetter, W., 2011. High-speed counter-current chromatographic separation of phytosterols. Anal. Bioanal. Chem. 400, 3615-3623.

Shehzad, O., Khan, S., Ha, I.J., Park, Y. \& Kim, Y.S., 2012. Rational development of a selection model for solvent gradients in single-step separation of ginsenosides from Panax ginseng using high-speed countercurrent chromatography. J. Sep. Sci. 35, 1462-1469.

Sun, A., Zhang, Y.Q., Li, A.F., Meng, Z.L. \& Liu, R.M., 2011. Extraction and preparative purification of tanshinones from Salvia miltiorrhiza Bunge by high-speed counter-current chromatography. J. Chromatogr. B: Anal. Technol. Biomed. Life Sci. 879, 1899-1904.

Tian, G., Zhang, Y., Zhang, T., Yang, F. \& Ito, Y., 2000. Separation of tanshinones from Salvia miltiorrhiza Bunge by high-speed counter-current chromatography using stepwise elution. J. Chromatogr. A 904, 107-111.

Vergara, C., Baer, D., Mardones, C., Wilkens, A., Wernekinck, K., Damm, A., Macke, S., Gorena, T. \& Winterhalter, P., 2012. Stilbene levels in grape cane of different cultivars in southern Chile: Determination by HPLCDAD-MS/MS method. J. Agric. Food Chem. 60, 929-933.
Wang, W., Tang, K., Yang, H.R., Wen, P.F., Zhang, P., Wang, H.L. \& Huang, W.D., 2010. Distribution of resveratrol and stilbene synthase in young grape plants (Vitis vinifera L. cv. Cabernet Sauvignon) and the effect of UV-C on its accumulation. Plant Physiol. Biochem. 48, 142-152.

Xiao, X.H., Si, X.X., Tong, X. \& Li, G.K., 2011. Preparation of flavonoids and diarylheptanoid from Alpinia katsumadai hayata by microwaveassisted extraction and high-speed counter-current chromatography. Sep. Purif. Technol. 81, 265-269.

Yan, Y., Yang, J.Y., Mou, Y.H., Wang, L.H., Zhou, Y.N. \& Wu, C.F., 2012. Differences in the activities of resveratrol and ascorbic acid in protection of ethanol-induced oxidative DNA damage in human peripheral lymphocytes. Food and Chem. Toxicol. 50, 168-174.

Yáñez, M., Fraiz, N., Cano, E. \& Orallo, F., 2006. (-)-Trans- $\varepsilon$-viniferin, a polyphenol present in wines, is an inhibitor of noradrenaline and 5-hydroxytryptamine uptake and of monoamine oxidase activity. Eur. J. Pharmacol. 542, 54-60.

Yao, S., Cao, Y., Jia, C.M., Wang, Y. \& Song, H., 2012. Developments of instruments and methods related with high-speed countercurrent chromatography and their applications in research of natural medicines. Cent. Eur. J. Chem. 10, 417-432.

Zhang, J.K., Zhu, X.Y., Luo, F.L., Sun, C., Huang, J.Z., Li, X. \& Chen, K.S., 2012. Separation and purification of neohesperidin from the albedo of Citrus reticulata $\mathrm{cv}$. Suavissima by combination of macroporous resin and high-speed counter-current chromatography. J. Sep. Sci. 35, 128-136. 